\title{
CONCEPTUAL DESIGN OF LASER ASSISTED FIXTURE FOR BENDING OPERATION
}

\author{
B.N.Nagendra Kumar ${ }^{1}$, Shailesh P. S ${ }^{\mathbf{2}}$, Ramesh Babu.K ${ }^{\mathbf{3}}$, Arvind Rao M Yadwad ${ }^{\mathbf{4}}$ \\ ${ }^{1}$ Dept of Mechanical Engineering, NIE, Mysore, Karnataka, India \\ ${ }^{2}$ Dept of Tool Engineering, G.T\&T.C, Mysore, Karnataka, India \\ ${ }^{3}$ Dept of Tool Engineering, G. $T \&$ \& . C, Mysore, Karnataka, India \\ ${ }^{4}$ Dept of Mechanical Engineering, NIE, Mysore, Karnataka, India
}

\begin{abstract}
Laser forming process is used in forming and bending of metallic and non metallic sheets. Laser beam irradiation causes a localized temperature increase and a localized mechanical strength decreases. In this article an external force has assisted laser to gain $90^{\circ}$ bending angle. The conceptual design of the fixture for bending thin metal sheets is designed with the help of Solid Works software to generate $3 D$ model. Also the calculations are computed for the fixtures.
\end{abstract}

Keywords: External force assisted laser forming process, bending angle, 3D model of Solid Works software.

\section{INTRODUCTION}

In laser forming (LF) process, which is shown in Fig. 1, laser beam is irradiated with a specific velocity in a desirable path. Because of a steep temperature gradient along the sheet thickness, thermal stresses are induced in the irradiated zone and a plastic deformation is produced. After the laser beam scan passes the work piece, it begins to cool and as a result, a permanent bending angle develops. Repetition of laser beam irradiation leads to increased bending angle [1]. To achieve higher bending angles it's required to increase the number of scan passes. However, this leads to excessive process time and increased production cost. Particularly, bending angle of the last passes is significantly smaller than of first ones. This phenomenon is attributed to some factors such as strain hardening, changes in laser beam absorption of the work piece, cross section thickening, thermal effects and geometrical effects of laser beam.

Since LF process is not recommended for achieving higher bending angles, the idea of applying an external force along with the laser beam irradiation was formed. Laser beam irradiation causes a localized temperature increase and a localized mechanical strength decrease. Thus, adding an external force enables increased bending angle per pass. In this article, focus is made to integrate a mechanical force to a LF process to obtain a 90-degree bending angle on thin metal sheets. For this reason, a suitable fixture is designed to restrict sheet movement and to apply mechanical force during process.

\section{PROCESS THEORY}

Laser forming mechanisms are specified, based on the temperature distribution in laser irradiated zone. This temperature distribution depends on process parameters such as laser power, beam diameter, scan velocity and sheet thickness. There are three laser forming mechanisms: Temperature Gradient Mechanism (TGM), Buckling Mechanism (BM) and Upsetting Mechanism (UM). In the experiment and numerical simulations, which is performed in this article, process parameters are selected in such a way that the TGM was active. A schematic image of this mechanism is shown in Fig.1. 3.

TGM is the most common mechanism used in LF process .Because of a relative rapid heating of the sheet surface by a laser beam and slow thermal conduction to the lower layers (especially in thicker sheets), a large temperature gradient develops in the thickness direction of the sheet. So, thermal expansion of the heated upper layers is much more than that of lower layers. It can be seen from the Fig. 3(b) that, at the beginning of the process, the sheet bends away from the laser beam. This is called counter bending and is a non-permanent bending angle. Further heating causes a decrease of mechanical strength in the heated zone. When thermal strains reach the maximum elastic strains, further thermal expansion converts into the plastic compressive strains; this is because free thermal expansion of the heated zone is limited by surrounding zone. In cooling process, as is shown in Fig. 3(c), upper layers contract and also endure a localized shortening due to the compressive stresses. This results to a permanent bending angle toward the laser beam. Bending angle magnitude is affected by these parameters: incident laser beam power, laser beam diameter, power density distribution of the laser beam, absorptive of laser beam on a material surface, scanning speed of laser beam, number of repetitions of laser beam scans, density of material, specific heat capacity of the 
material, thermal expansion coefficient, yield strength, Young's modulus, Poisson's ratio, strain hardening coefficient, geometrical dimensions of the work piece, melting temperature and the fracture strength of the material.

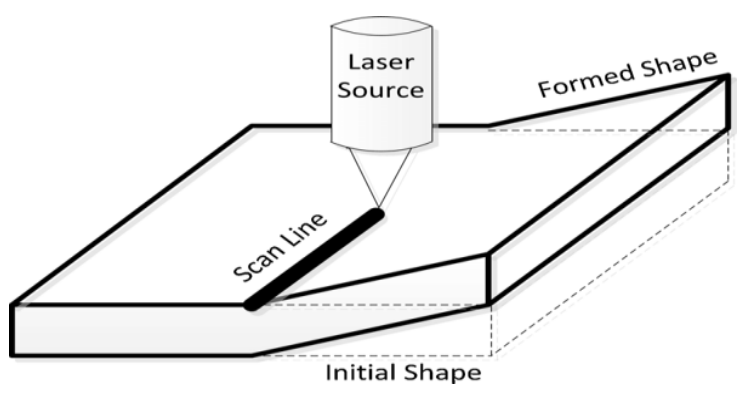

Fig.1.1 Schematic image of laser forming process

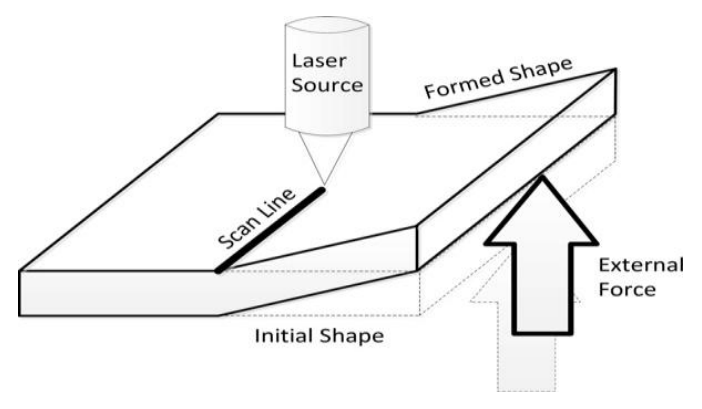

Fig.1.2. Schematic image of external force-assisted laser forming process
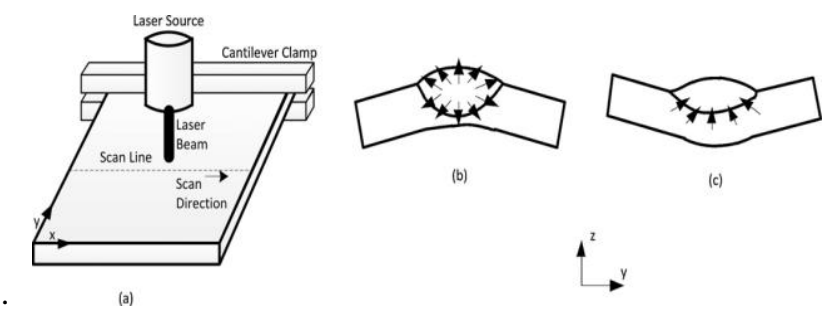

Fig.1.3. Laser forming process steps with TGM: (a) process model; (b) heating process (counter bending) (c) cooling process (permanent bending angle).

\section{EXPERIMENTAL SETUP}

To design a fixture that lifts the worktable upwards after laser beam scan pass to bend thin metal sheets up to $90^{\circ}$ with the help of external forces, following mechanisms are incorporated in the fixture. They are

1. Spring assisted bell crank lever mechanism

2. Peauciller mechanism

3. Cam assisted toggle mechanism

With the help of this mechanism we have designed a manually operated fixture to bend thin metal sheets. For this purpose, the fixture is designed in solid works software 2013 to generate 3D model. Three types of 3D model and calculations are demonstrated in this article.

\subsection{Bell Crank Lever Mechanism}

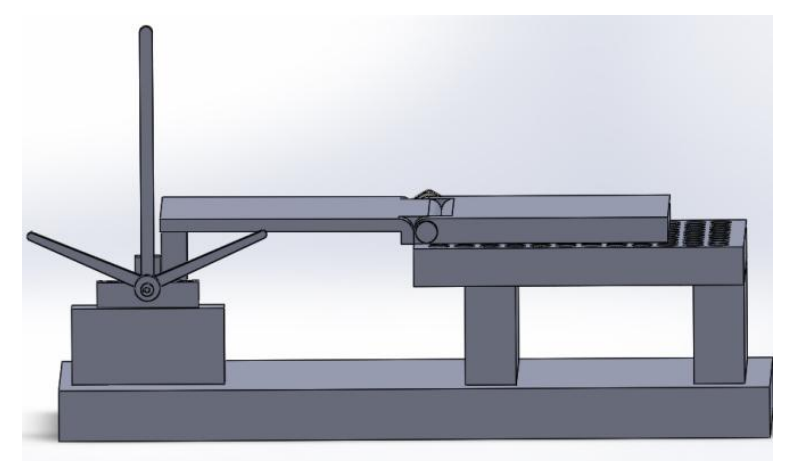

Fig 2.1.a. shows front view of the fixture

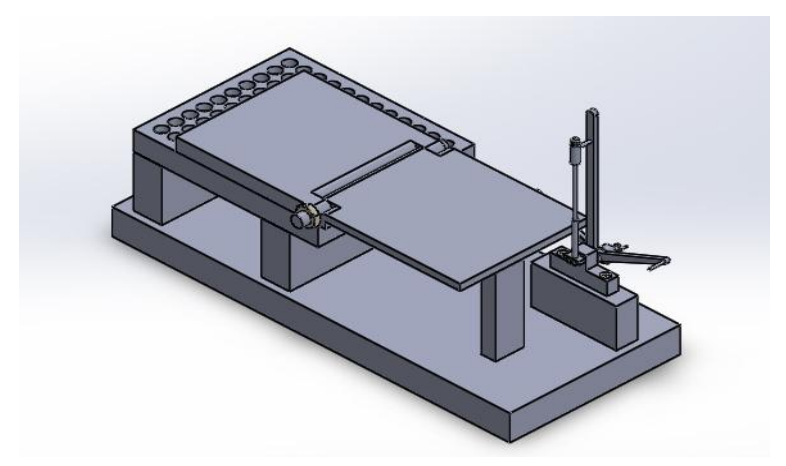

Fig 2.1.b. shows top view of the fixture

Fig 2.1.a. manually operated fixture consists of a base of size $280 \times 120 \mathrm{~mm}$ and thickness of about $20 \mathrm{~mm}$. The base consists of three support stands and bell crank lever mechanism stand. The work table consists of two parts which are in equal size of $100 \times 90 \mathrm{~mm}$ and thickness of $10 \mathrm{~mm}$. One part is fixed to support block mounted on the two support stand and the other work table would move freely upwards. The two parts of the table are joined by $8 \mathrm{~mm}$ diameter shaft and bolted tightly. Thin sheets are clamped on the worktable positively and ready for the next process. Remaining one support stand helps to avoid the downward movement of the work table.

In bell crank lever mechanism, assembly consists of bell crank lever, over hang crank, helical spring, hand wheel, stand and supporting link for overhang crank.

Helical spring is designed and placed on the supporting link, which is connected to the overhang crank of $5 \mathrm{~mm}$ in length. When hand wheel starts to rotate in clock wise direction, helical spring will fluctuate on the supporting link of overhang crank and starts to rotate in same direction to lift the worktable up to $90^{\circ}$. Bell crank lever having same length of lever that is, $50 \mathrm{~mm}$ helps in lifting the worktable. 


\subsubsection{Design of bell crank lever}

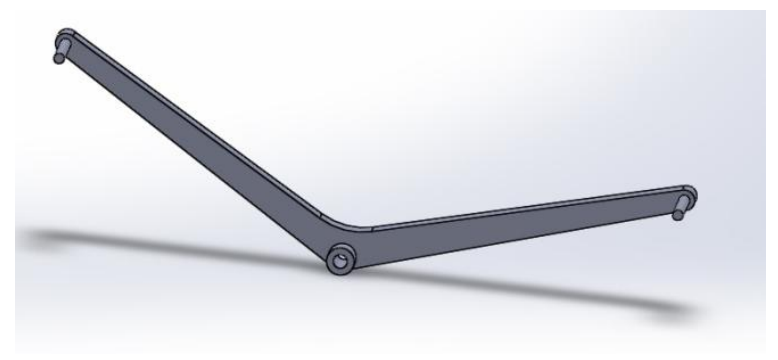

Fig 2.1.c. shows design of bell crank lever

Select the material as Mild Steel having maximum tensile stress that is 400 to $560 \mathrm{~N} / \mathrm{mm}^{2}$ and yield stress between 300 to $440 \mathrm{~N} / \mathrm{mm}^{2}$. Assume permissible bearing pressure as 10 $\mathrm{N} / \mathrm{mm}^{2}$ and apply load of $1 \mathrm{~kg}(9.81 \mathrm{~N})$. For balancing take both length $l_{1}$ and $l_{2}$ as $50 \mathrm{~mm}$ and factor of safety (n) for steady load is 4 .

Step 1: Force Analysis

$$
\mathrm{F} \times \mathrm{l}_{2}=\mathrm{P} \times \mathrm{l}_{1}
$$

Where $\mathrm{F}$ and $\mathrm{P}=$ force in $\mathrm{N}$

$\mathrm{l}_{1}$ and $\mathrm{l}_{2}=$ length in $\mathrm{mm}$

$9.81 \times 50=\mathrm{P} \times 50$

$\mathrm{P}=9.81 \mathrm{~N}$

Step 2: Reaction force (R)

$$
R=\sqrt{ } F^{2}+R^{2}-2 F R \cos \varnothing
$$

Assume $\varnothing=135^{\circ}$

$\mathrm{R}=9.81^{2}+9.81^{2}-2 \times 9.81 \times 9.81 \times \cos 135$

$\mathrm{R}=18.12 \mathrm{~N}$.

Step 3: diameter $\left(D_{1}\right)$ and length $\left(L_{1}\right)$ of fulcrum pin In general length to diameter ratio $L_{1} / D_{1}$ is 1 to 2 . For safety purpose I should take 1.5.

$$
\mathrm{R}=\mathrm{p}\left(\mathrm{D}_{1} \times \mathrm{L}_{1}\right)
$$

Where $\mathrm{p}=$ permissible bearing pressure

$18.12=10\left(\mathrm{D}_{1} \times 1.5 \mathrm{D}_{1}\right)$

$\mathrm{D}_{1}=1.099 \mathrm{~mm}$

$\mathrm{L}_{1}=1.5 \times \mathrm{D}_{1}=1.5 \times 1.099=1.64 \mathrm{~mm}$

Since the output obtained is small and outer diameter (D) of the pin is double of the inner diameter of the pin. That is $D=$ $2 \mathrm{D}_{1}$. Hence, the inner and outer diameter of the pin is $2 \mathrm{~mm}$ and $4 \mathrm{~mm}$ respectively.

Step 4: check for the stress

Factor of safety(n) for steady load $=4$

(a) Permissible stress $\left(\sigma_{\mathrm{b}}\right)$ $\sigma_{\mathrm{b}}=$ ultimate tensile strength $/ \mathrm{n}$

$=400 / 4=100 \mathrm{~N} / \mathrm{mm}^{2}$.

(b) Shear stress $\left(\mathrm{T}_{\mathrm{s}}\right.$

$\mathrm{T}_{\mathrm{s}}=50 \%$ of ultimate tensile strength $/ \mathrm{n}$

$=0.5 \times 400 / 4=50 \mathrm{~N} / \mathrm{mm}^{2}$

(c) Compressive Stress

$\sigma_{c}=R /\left(D_{1} \times L_{1}\right)=9.81 /(1.099 \times 1.64)$

$=5.44 \mathrm{~N} / \mathrm{mm}^{2}$

(d) Pin is subjected to double shear

$\mathrm{T}=\mathrm{R} /\left(2 \times \pi \times \mathrm{D}_{1}^{2} / 4\right)=18.21 /\left(2 \times \pi \times 1.099^{2} / 4\right)$

$=9.59 \mathrm{~N} / \mathrm{mm}^{2}$

From this calculation it is seen that the pin is subjected to double shear and is less than the shear stress of the material. Hence the design is safe.

\subsubsection{Design of Helical Spring}

Assume the material of the spring be Flat spring steel having ultimate tensile stress as 1100 to $2210 \mathrm{~N} / \mathrm{mm}^{2}$ and modulus of rigidity $(\mathrm{G})$ as $82 \mathrm{Gpa}$.Select the spring index(c) as 6 and minimum force $\left(\mathrm{F}_{\min }\right)$ and maximum force $\left(\mathrm{F}_{\max }\right)$ be $9.81 \mathrm{~N}(1 \mathrm{~kg})$ and $98.1 \mathrm{~N}(10 \mathrm{~kg})$ respectively. Also permissible shear stress is $50 \%$ of ultimate tensile stress. i.e 827.5 $\mathrm{N} / \mathrm{mm}^{2}(50 \%$ of 1655$)$.

- Stress correction factor according to Wahl(k)

$$
\mathrm{k}=\frac{4 c-1}{4 c-4}+\frac{0.615}{c}
$$

where $\mathrm{c}=$ spring index $=6$

$\mathrm{k}=\frac{4(6)-1}{4(6)-4}+\frac{0.615}{6}=1.2525$

- $\quad$ Shear stress(T) in helical spring

$\mathrm{T}=\mathrm{k}\left(\frac{8 F \max C}{\pi d 2}\right)$

$827.5=1.2525\left(\frac{8 \times 98.1 \times 6}{\pi d 2}\right)$

$\mathrm{d}=1.5=2 \mathrm{~mm}$

- Mean coil diameter(D)

$\mathrm{D}=\mathrm{Cd}$

$\mathrm{D}=6 \times 2=12 \mathrm{~mm}$

- $\quad$ Number of active coils $(\mathrm{N})$

Assume maximum force apply to $10 \mathrm{~mm}$

$\delta=8 \mathrm{FmaxD}^{3} \mathrm{~N} / \mathrm{Gd}^{4}$ 
$10=\left(8 \times 98.1 \times 12^{3} \mathrm{~N}\right) /\left(82000 \times 2^{4}\right)$

$\mathrm{N}=9.67=10$

- Total number of active coils

It is assumed that the spring has square and ground ends. The number of inactive coil is 2 .

$\mathrm{Nt}=\mathrm{N}+2=10+2=12$

- $\quad$ Free length of the spring $(\delta)$

$\delta=8 \mathrm{Fmax}^{3} \mathrm{~N} / \mathrm{Gd}^{4}$

$=\left(8 \times 98.1 \times(12)^{3} \times 10\right) /\left(82000 \times 2^{4}\right)$

$=10.33 \mathrm{~mm}$.

- Solid length of the spring

$\mathrm{Nt} \times \mathrm{d}=12 \times 2=24$

- It is assumed that there will be gap of $1 \mathrm{~mm}$ between consecutive coils. when the spring subjected to maximum force total number of coils(n) is 12 .

Total axial gap between each coils $=(n-1) \times t=(12-$ 1) $\times 1=11 \mathrm{~mm}$

- $\quad$ Length of the spring $=$ solid length + total axial gap $+\delta$ (16)

$=24+11+10.33=45.33 \mathrm{~mm}$

- $\quad$ Pitch coil $=\frac{\text { Free lengt } h}{N t-1}=\frac{45.33}{12-1}$

$$
=4.12 \mathrm{~mm}
$$

- $\quad$ Spring scale $=\frac{F m a x-F m i n}{\delta}$

$=\frac{98.1-9.81}{10}$

$=8.83 \mathrm{~N} / \mathrm{mm}^{2}$

\subsubsection{Design of Overhang Crank}

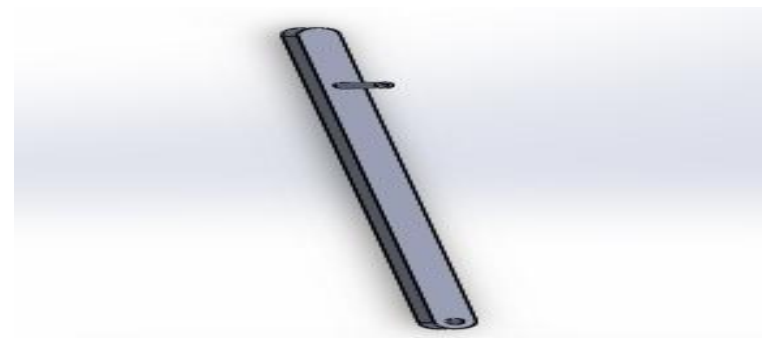

Fig2.1.d. shows design of overhang crank

Select the material as mild steel and properties of mild steel are mentioned in 1.1 section.

- Bending moment $\mathrm{M}_{\mathrm{b}}=1 \times(30+10+5)=45 \mathrm{~N}-\mathrm{mm}$.

(19)

- Torsional moment $\mathrm{M}_{\mathrm{t}}=1 \times 75$
$=75 \mathrm{~N}-\mathrm{mm}$.

- Bending stress $\sigma_{b}=M_{b} y / I$ $=(45 \times(\mathrm{d} / 2)) /\left(\pi \times \mathrm{d}^{4} / 64\right)=458.3 / \mathrm{d}^{3} \mathrm{~N} / \mathrm{mm}^{2}$

- Torsional stress $T=\mathrm{M}_{\mathrm{t}} \mathrm{r} / \mathrm{J} \quad$ (22)

$$
=(75 \times \mathrm{d} / 2) /\left(\pi \times \mathrm{d}^{4} / 32\right)=381.97 / \mathrm{d}^{3} \mathrm{~N} / \mathrm{mm}^{2}
$$

- From Mohr's circle

$$
\tau_{\max }=\sqrt{\left(\frac{\sigma b}{2}\right)^{2}+T^{2}}
$$

Substitute equation 1.22and 1.23 to 1.24 we get $T_{\max }=$ $445.43 / \mathrm{d}^{3}$. Since $T_{\max }$ is $50 \%$ of ultimate tensile strength of mild steel. i.e $50 \mathrm{~N} / \mathrm{mm} 2$

$50=445.43 / \mathrm{d}^{3}$

$\mathrm{d}=2.07 \mathrm{~mm}=2 \mathrm{~mm}$ where $\mathrm{d}$ is diameter

Once the diameter is known the bending stress and torsional stress will be $57.28 \mathrm{~N} / \mathrm{mm}^{2}$ and $47.74 \mathrm{~N} / \mathrm{mm}^{2}$ respectively. Hence the diameter obtained in bell crank lever calculation is same as in the diameter of overhang crank calculation Also design is safe.

\subsection{Peaucellier Mechanism}

From the fig 2.2.a fixture consists of a base of size $170 \times 350$ $\mathrm{mm}$ and thickness of about $20 \mathrm{~mm}$. The base consists of four support stands two of which are larger in size of $90 \times 20 \mathrm{~mm}$ and height $70 \mathrm{~mm}$ and other two are smaller in size of $15 \times 10 \mathrm{~mm}$ and height $60 \mathrm{~mm}$. Also base consists of guide pillar $8 \mathrm{~mm}$ diameter and height of $130 \mathrm{~mm}$. These are connected to hand wheel by connecting rod of length of $150 \mathrm{~mm}$ and are rotated manually with hand. The hand wheel is fixed on the shaft $5 \mathrm{~mm}$ diameter and length $20 \mathrm{~mm}$ which are mounted on the hand wheel stand.

The peauciller mechanism links are mounted on the smaller support stand to lift the work table upwards up to $90^{\circ}$. This consists of 6links. Four of which are equal in size of about $60 \mathrm{~mm}$ and are linked together by rhombus angle and two are larger in length of $105 \mathrm{~mm}$. One of the four smaller links are connected to guide pillar by means side link $60 \mathrm{~mm}$ in length to move up and down while hand wheel rotates in clock wise direction. The work table consists of two parts which are in equal size of $100 \times 90 \mathrm{mmand}$ thickness of $10 \mathrm{~mm}$. One part is fixed to support block mounted on the larger support stand and other work table is move freely upwards. The two parts of the table are joined by $8 \mathrm{~mm}$ diameter shaft and bolted tightly. Thin sheets are clamped on the worktable positively and ready for the next process. 


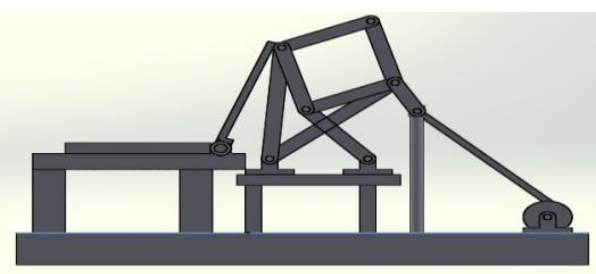

Fig 2.2.a. shows work table lift with the help of peauciller mechanism.

The pin $\mathrm{Q}$ is constrained to move along the circumference of circle by means of the link OQ. The link OQ and OA is fixed are equal in length.i.e.,60mm. Pin $\mathrm{P}$ and $\mathrm{Q}$ are in opposite corners of a four bar chain which has all four links QC, CP, $\mathrm{PB}$ and $\mathrm{BQ}$ are equal in length. i.e., $60 \mathrm{~mm}$. The pin $\mathrm{B}$ and $\mathrm{C}$ are connected by links of equal length to fixed pin A. i.e., link $\mathrm{AB}=$ link $\mathrm{AC}=105 \mathrm{~mm}$. The product of $\mathrm{AQ}$. $\mathrm{AP}$ remains constant as the link OQ rotates may be proved as follows:

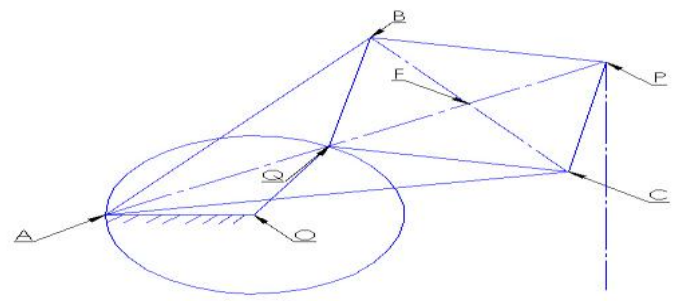

Fig 2.2.b. shows points named for peauciller mechanism

Join $\mathrm{BC}$ to bisect $\mathrm{PQ}$ at $\mathrm{F}$; from right angled triangle $\mathrm{AFB}$ and BFP

$$
\begin{aligned}
& \mathrm{AB}^{2}=\mathrm{AF}^{2}+\mathrm{FB}^{2} \\
& =(105)^{2}+(45)^{2}=13050 \mathrm{~mm}^{2} \\
& \mathrm{BP}^{2}=\mathrm{BF}^{2}+\mathrm{FP}^{2} \\
& =45^{2}+45^{2}=4050 \mathrm{~mm}^{2} \\
& \mathrm{AB}^{2}-\mathrm{BP}^{2}=\mathrm{AQ} \times \mathrm{AP} \\
& 13050-4050=60 \times 150 \\
& 9000 \mathrm{~mm}^{2}=9000 \mathrm{~mm}^{2}
\end{aligned}
$$

Since $\mathrm{AB}$ and $\mathrm{BP}$ links are constant length, the product $\mathrm{AQ}^{*} \mathrm{AP}$ is constant.

\subsection{Cam Assisted Toggle Mechanism}

Fig 2.3.a shows manually operated fixture consists of a base of size $350 \times 150 \mathrm{~mm}$ and thickness of about $20 \mathrm{~mm}$. The base consists of four support stands and hand wheel stand. The work table consists of two parts which are in equal size of $100 \times 90$ mmand thickness of $10 \mathrm{~mm}$. One part is fixed to support block mounted on the two support stand and other work table is moved freely upwards. The two parts of the table are joined by $8 \mathrm{~mm}$ diameter shaft and bolted tightly. Thin sheets are clamped on the worktable positively and ready for the next process. Remaining two support stands are connected with toggle mechanism links, such that one link are larger and two links are smaller in length of $90 \mathrm{~mm}$ and $60 \mathrm{~mm}$ respectively.

Push rod operated cam is designed to lift the work table assisted with toggle mechanism. The follower is connected with roller of $10 \mathrm{~mm}$ diameter to travel on the cam. The up face of the follower is connected to the joints of the two toggle mechanism links.

Since the fixture is manually operated, such that operated by the hand, while hand wheel starts to rotate in clock wise direction connecting rod connected to cam helps to rotate in same direction. This helps to lift the work table up to $90^{\circ}$.

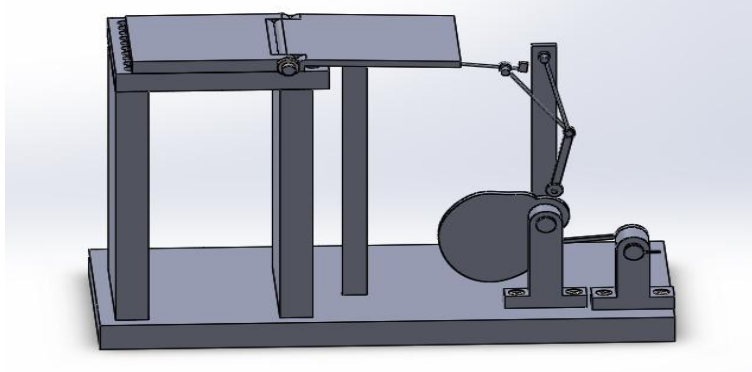

Fig.2.3.a shows front view of cam assisted toggle mechanism fixture.

\subsubsection{Design of the Cam}

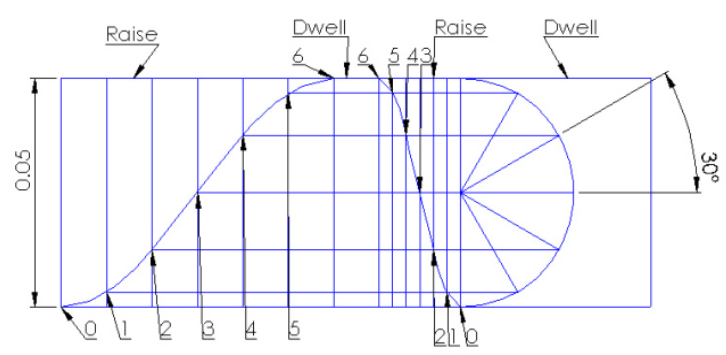

Fig 2.3.b. shows displacement diagram

From the above fig 3.3.b raise, dwell, raise and dwell are $90^{\circ}, 30^{\circ}, 60^{\circ}$ and $30^{\circ}$ respectively. 


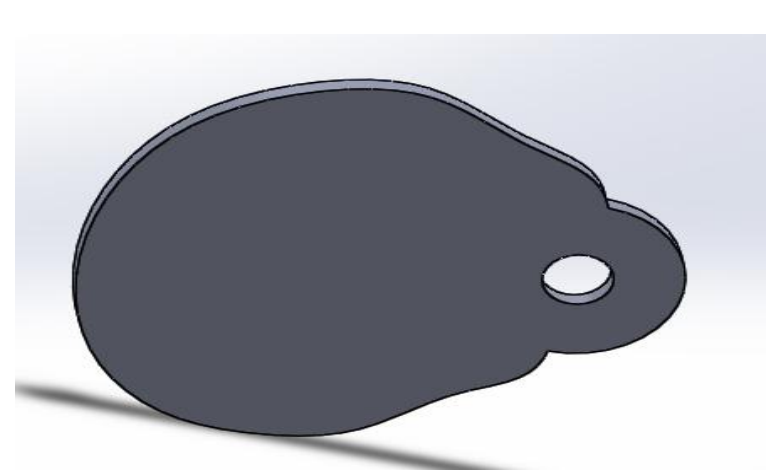

Fig 2.3.c.shows design of cam

Assume the Push rod operated by Cam is to raise and fall with simple harmonic motion along straight path. Take Cam diameter and push rod diameter as $30 \mathrm{~mm}$ and $10 \mathrm{~mm}$ respectively. Maximum displacement of roller is 46 to $50 \mathrm{~mm}$. Cam rotates at $100 \mathrm{rpm}$ in clock wise direction. Time to lift and time of fall be 0.15 and $0.1 \mathrm{sec}$ with a rest of period of $0.05 \mathrm{sec}$.

From Calculations:

In one second the cam make 100/60 revolution $=100 / 60 \mathrm{sec}$.

Ascent $=0.15 \mathrm{sec}=100 \times 360 \times 0.15 / 60=90^{\circ}$

Fall or dwell $=0.1 \mathrm{sec}=100 \times 360 \times 0.1 / 60=60^{\circ}$

Upper dwell $=0.05 \mathrm{sec}=100 \times 360 \times 0.05 / 60=30^{\circ}$.

\subsubsection{Velocity Analysis For Toggle Mechanism}

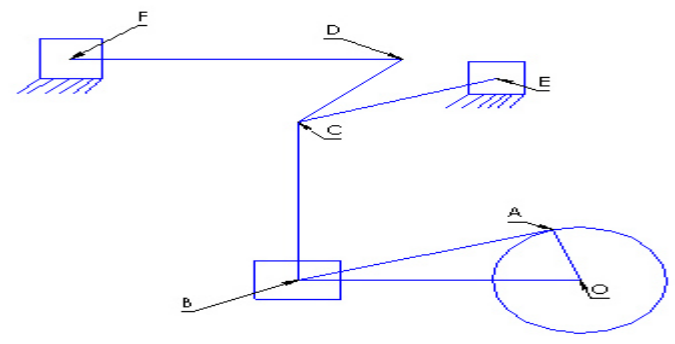

Fig 2.3.c shows space diagram for toggle mechanism.

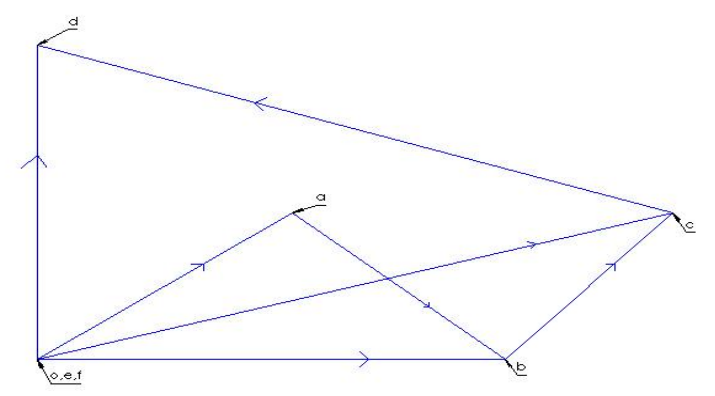

Fig 3.3.d shows velocity analysis for toggle mechanism
Scale $1 \mathrm{~cm}=5 \mathrm{~mm}=0.05 \mathrm{~m}$

Assume crank rotates in clock wise at 100rpm.

- $\quad \mathrm{V}_{\mathrm{a}}=2 \times \pi \times 100 / 60=0.16 \mathrm{~m} / \mathrm{sec}$

From velocity diagram

- Velocity of slider $B \mathrm{~V}_{\mathrm{b}}=\mathrm{ab} \times$ scale $=2 \times 0.05=0.1 \mathrm{~m} / \mathrm{sec}$

- Velocity of slider $\mathrm{C}_{\mathrm{c}}=02 \mathrm{~b} \times$ scale $=2 \times 0.05=0.1 \mathrm{~m} / \mathrm{sec}$

- Velocity at $\mathrm{E}=\mathrm{oc} \times \mathrm{scale}=$ $5.9 \times 0.05=0.295 \mathrm{~m} / \mathrm{sec}$

- Velocity of slider $\mathrm{D}=\mathrm{cd} \times$ scale $=5.5 \times 0.05=0.2750 \mathrm{~m} / \mathrm{sec}$

- Velocity at $\mathrm{F}=\mathrm{fd} \times$ scale $=3.4 \times 0.05=0.017 \mathrm{~m} / \mathrm{sec}$

\section{CONCLUSIONS}

Fixture planning is a complex activity affected by the extreme diversity of work pieces and several factors. Generally, the fixture planning consists of four phases: the problem description, fixture analysis, fixture synthesis, and fixture verification.

Fixture analysis and verification methods are summarized as geometrical analysis, kinematic analysis, force analysis, and deformation analysis. In fixture synthesis, assembly sequence planning methods, and optimization methods are surveyed .This paper addresses the manually operated fixture design planning by using the Solid works software to verification issue, the work piece location, clamping stability under dynamic machining and frictional conditions at the interface in fixture elements and work piece are taken into account.

Concluding contributions of this paper in the area of jigs and fixture design are

- Fixture design under machining effect, and its manufacturing considerations

- To economize the operation in the model.

- $\quad$ Optimize the process

\section{REFERENCES}

[1]. Amir.H.Rochi,M.HoseinpourGolloTarbiat Modares University, Tehran ,Iran.External force assisted laser forming process for gaining high bending angles.Journal of manufacturing process $14(2012)$ 269-276.

[2]. Gigliola lubiano, Jorge A.Ramos, Dept of mechanical \& metarllurgical engg, Portificia university, Chile .Laser bending of thin metal sheets by means of a low power $\mathrm{CO} 2$ laser.

[3]. Ferdinand Bammer, Thomas Schumi, Andreas Otto, Dieter Schuöcker Laser assisted bending for efficient lightweight-production. ISSN 1330-3651. 
[4]. Pei Jibin, Zhang Liwen, Wang Cunshan and Dong Chuang, Department of Materials Engineering, Dalian University of Technology, Dalian, 116024, P. R. China.

Numerical simulation and experimental investigation of laser bending of steel plate. International Symposium Research Students on Material Science and Engineering December 2022,2004, Chennai, India,

[5]. Design of machine elements-1 by Prof J.B.K.DAS and P. L. Srinivasmurthy. ISBN:81-280-0237-6.

[6]. Design of machine elements, third edition by V B Bhndari .ISBN-13: 978-0-07-068179-8.

[7]. Design Data Hand Book, third edition by K. Mahadevan and K. Balaveera Reddy. ISBN :81-239-0162-3.

[8]. Kinematics of Machines by Prof J.B.K.DAS and P. L. Srinivasmurthy. ISBN:978-81-280-0221-2. 